\title{
Fuel Management and Control in a Vehicular System
}

\author{
S.Bhavanisankari, G.T.Bharathy, T.Tamilselvi, G.Bhargavi
}

\begin{abstract}
This project simulates a working model of a vehicular system which gives a good tradeoff between power, economy and emissions. The optimum air-fuel ratio for this system to be designed is 14.6. The quantity of oxygen content in the exhaust gas (EGO) is obtained with the help of a sensor. The output from this sensor is a sign of air fuel ratio and it gives the necessary feedback for closed loop control. When high oxygen level is shown by the sensor, then as per the control law, the fuel rate will be increased. Subsequently if the sensor indicates a fuel rich mixture, when the level of residual oxygen is very low, then this leads to reduction in fuel rate.
\end{abstract}

\section{Index Terms: Subsystems, Engine control unit, Fuel}

\section{INTRODUCTION}

This project is about the physical and empirical relationships for the throttle and intake manifold model. In order to calculate the air fuel ratio, the air mass flow rate is divided by fuel mass flow rate. This ratio provides good power, economy and emission. Standard air-fuel ratio is 14.6. The quantity of oxygen content in the exhaust gas(EGO) is obtained with the help of a sensor. The output from this sensor is a sign of air fuel ratio and it gives necessary feedback for closed loop control. When high oxygen level is sensed by the sensor, fuel rate is increased by the controller. If low oxygen level is sensed by the sensor, fuel rate is decreased by the controller.

\section{SYSTEM DESIGN}

\section{A. Dashboard Subsystem}

During simulation the dashboard subsystem allows the user to interact with the model. To simulate sensor failures the fault switches can be stirred from the regular to faulty position while in order to change the engine speed, the engine speed selector switch can be toggled. During a simulation run to provide visual feedback, the dashboard gauges and scopes are used to see air/fuel ratio along with the fuel signals.

The stoichiometric mixture ratio is obtained from fuel rate given by the signals from the sensors employed by the fuel

S.Bhavanisankari, Electronics and Communication Engineering, Jerusalem College of Engineering, Chennai, India.

G.T.Bharathy, Electronics and Communication Engineering, Jerusalem College of Engineering, Chennai, India.

T.Tamilselvi, Electronics and Communication Engineering, Jerusalem College of Engineering, Chennai, India.

G.Bhargavi, Electronics and Communication Engineering, Jerusalem College of Engineering, Chennai, India. rate subsystem. In order to obtain the final mixture ratio which is sensed at the exhaust level, the realistic air flow as seen in the engine dynamics model is mixed with the fuel rate. By using slider switch in the dashboard system user can disable each of the four sensors i.e throttle angle, speed, EGO, MAP

(manifold absolute pressure) to simulate failures. It is

accomplished in simulink by fastening slider switches to the value parameter of the constant block.
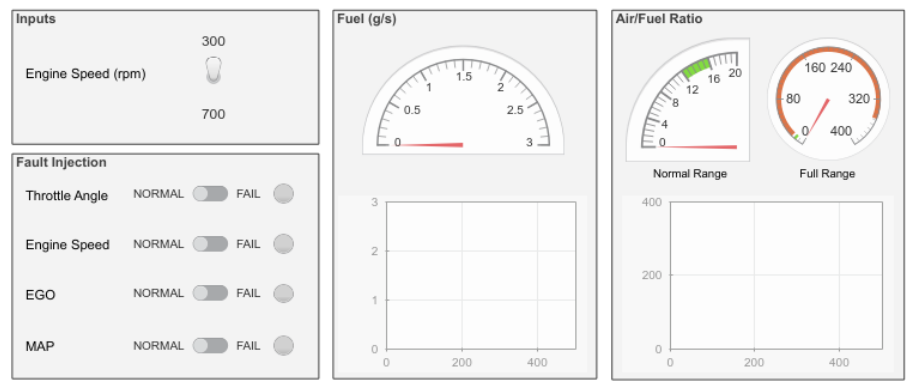

Fig 1. Dashboard subsystem

This model uses three subsystems namely control logic, airflow calculation and fuel calculation. In ordinary condition the model calculates the airflow rate and multiplies the rate with the reciprocal of the ratio to give the fuel rate. A feedback from oxygen sensor provides closed-loop alteration of the rate evaluation for the purpose of sustaining the ratio.

\section{B. Control Logic}

A single Stateflow Chart consists of six parallel states that forms the control logic. There are four parallel states each of which are four individual sensors. The other two states below is used to estimate the entire operating mode of the system. The mode synchronously activates the whole Stateflow diagram at a sampling time interval of 0.01 secs which allows the environment for transition to be tested on time basis.

During execution, all the states begin in the respective normal mode except the oxygen sensor (EGO). Initially, until the warmup period is complete the $\mathrm{O} 2$ warmup state is entered. During oxygen sensor warmup the system maintains the mixture at normal level.

The bottom parallel plate characterizes the fueling mode of the engine. When one sensor fails in the system, the operation goes on undisturbed but air/fuel mixture is comparatively more for smoother allowance running at a cost of higher emission of fuel.

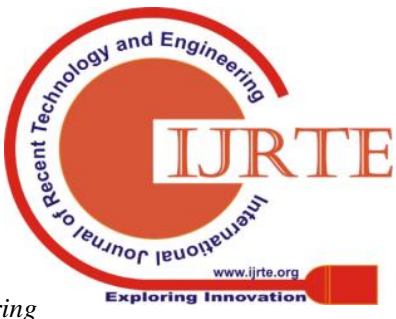




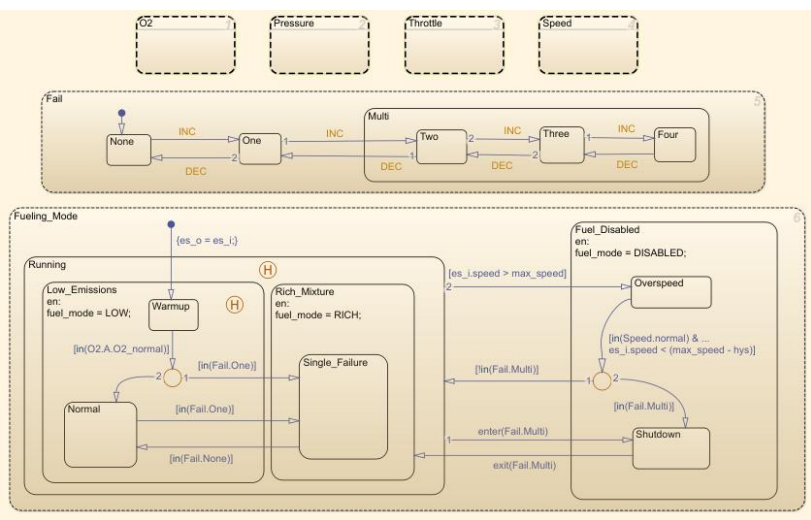

Fig 2. Control logic subsystem

\section{RESULTS AND CONCLUSION}

\section{A. Airflow Calculation}

Airflow calculation block is found inside the fuel rate control subsystem. In this block the intake air flow is eliminated to estimate the fuel rate which gives the approximate air/fuel ratio. To maintain the mixture ratio the closed-loop control adjusts the estimation with respect to the residual oxygen feedback. The most recent closed-loop adjustment is retained when a sensor fails in open-loop operation.

\section{Equation 1}

$\mathrm{q}=\frac{N}{4 \pi} \mathrm{V}_{\mathrm{cd}} \mathrm{V} \frac{P m}{F T}=\mathrm{C}_{\text {pump }}\left(\mathrm{N}, \mathrm{P}_{\mathrm{m}}\right) \mathrm{NP}_{\mathrm{m}}$

$\mathrm{N}=$ Engine Angular Speed $(\mathrm{Rad} / \mathrm{sec})$

$\mathrm{V}_{\mathrm{cd}}=$ Engine cylinder displacement volume

$\mathrm{v}=$ Volumetric efficiency

$\mathrm{P}_{\mathrm{m}}=$ Manifold pressure

$\mathrm{R}, \mathrm{T}=$ Specific gas constant, gas temperature

\section{Equation 2}

$$
\begin{aligned}
& \mathrm{e}_{0}=0.5 \text { for } \mathrm{EGO} \leq 0.5 \\
& \mathrm{e}_{0}=-0.5 \text { for } \mathrm{EGO}>0.5 \\
& \mathrm{e}_{1}=\mathrm{K}_{\mathrm{i}}\left(\mathrm{N}, \mathrm{P}_{\mathrm{m}}\right) \mathrm{e}_{0} \text { for } \mathrm{EGO} \leq 0.5 \\
& \dot{\mathrm{e}}_{2}=\mathrm{e}_{1} \text { for } \mathrm{LOW} \text { mode with valid EGO signal } \\
& \dot{\mathrm{e}}_{2}=0 \text { for RICH, DISABLE or EGO warmup }
\end{aligned}
$$

$\mathrm{e}_{0}, \mathrm{e}_{1}, \dot{\mathrm{e}}_{2}=$ Intermediate error signals

Air-fuel ratio is estimated using these equations and when applied to the system, it yields the ideal air fuel ratio.

\section{REFERENCES}

1. John R. Wagner, Member, IEEE, Darren M. Dawson, Senior Member, IEEE, and Liu Zeyu (2003), Nonlinear Air-to-Fuel Ratio and Engine Speed Control for Hybrid Vehicles.
2. Suzuki, K., Shen, T., Kako, J., \& Yoshida, S. (2009). Individual A/F Estimation and Control With the Fuel-Gas Ratio for Multicylinder IC Engines. IEEE Transactions on Vehicular Technology, 58(9), 4757-4768.

3. Zhixiang HOU, Yihu WU, IEEE (2007).The Research on Air Fuel Ratio Predictive Model of Gasoline Engine during Transient Condition

4. Shinsuke Takahashi, Teruji Sekozawa. Air-Fuel Ratio Control in Gasoline Engines Based on State Estimation and Prediction Using Dynamic Models.

5. Yao Ju-Biao, Research on Transient Air Fuel Ratio Control of Gasoline Engines (2009).

6. Chen Linlin, Wei Minxiang On Transient Air/fuel Ratio Control for Gasoline Engine on the Basis of Model Identification (2008).

7. HOU Zhi-xiang, Predictive Control for Air Fuel Ratio of Gasoline Engine based on Neural Network (2016).

\section{AUTHORS PROFILE}

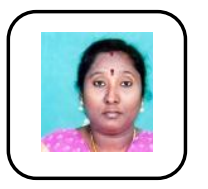

Ms.S.Bhavani Sankari was born in India in the year 1978. She completed B.E degree in Electronics and Communication Engineering from Thanthai Periyar Government College of Engineering, Madras University, India in the year 1995 and M.E degree in Industrial Electronics from Sri Jeyachamarajendra College of Engineering, Visveswaraya University, India in the year 2003. She is now working as an Associate Professor in Jerusalem College of Engineering, Dept. of Electronics and Communication Engineering, Chennai. She is a life member in ISTE. Her research interest is Communication, Signal Processing.

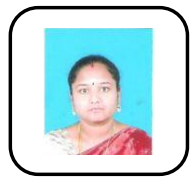

Ms.G.T.Bharathy was born in India in the year 1979. She completed B.E degree in Electronics and Communication Engineering from Easwari Engineering College, Chennai, Madras University, India in the year 2000 and M.E degree in Communication Systems from Shri Venkateshwara College of Engineering, Chennai, Anna University, India in the year 2005. She is now working as Senior Assistant Professor in Jerusalem College of Engineering, Dept. of Electronics and Communication Engineering, Chennai. She is a life member in ISTE. She has worked as Lecturer in the department of ECE in Anand Institute of Higher Technology and Prince Shri Venkateshwara Padmavathi College of Engineering, Chennai. Her research interest is RF and microwave circuits and systems.

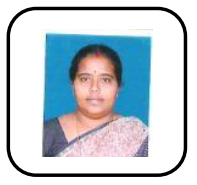

Ms.T.Tamilselvi was born in India in the year 1978. She completed B.E degree in Electronics and Communication Engineering from Adhiparasakthi Engineering College, Madras University, India in the year 2000 and M.E degree in Embedded System Technologies from College of Engineering, Guindy (CEG Main Campus), Anna University, India in the year 2006. She is now working as Senior Assistant Professor in Jerusalem College of Engineering, Dept. of Electronics and Communication Engineering, Chennai. She is a life member in ISTE. Her research interest is VLSI and Embedded design.

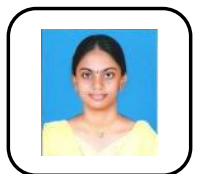

Ms.G.Bhargavi was born in India in the year 1987. She completed B.E degree in Electronics and Communication Engineering from Sri Muthukumaran Institute of Technology, Anna University, India in the year 2009 and M.E degree in Communication Systems from Shri Venkateshwara College of Engineering, Chennai, Anna University, India in the year 2011. She is now working as Assistant Professor in Jerusalem College of Engineering, Dept. of Electronics and Communication Engineering, Chennai. She is a life member in ISTE. Her research interest is Communication Systems.

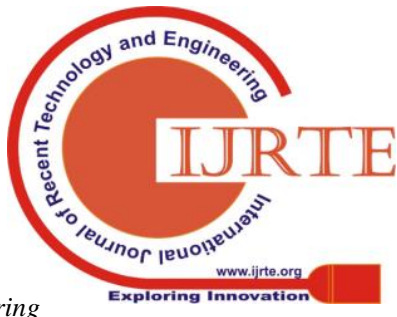

